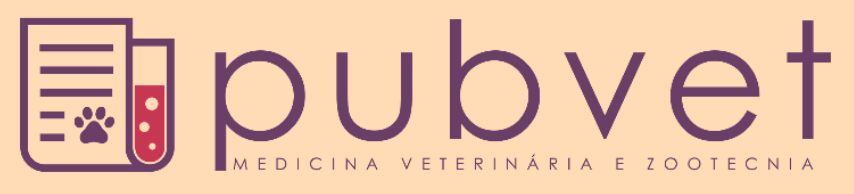

https://doi.org/10.31533/pubvet.v13n3a285.1-14

\title{
Abate humanitário e insensibilização em bovinos na perspectiva da medicina veterinária legal: Revisão
}

\author{
Jackson Barros do Amaral ${ }^{1 *}$, Tália Missen Tremori $^{2}{ }^{\bullet}$, Alessandra Santos d'Alencar $^{3} \bullet$, \\ Guilherme Trevisan ${ }^{4} \theta$
}

${ }^{1}$ Médico Veterinário, Pesquisador Científico, Secretaria de Agricultura e Abastecimento - SAA do Estado de São Paulo, Instituto de Zootecnia - Centro de Pesquisa de Bovinos de Leite, Rua Heitor Penteado, 56, CP 60, Nova Odessa-SP, Brasil, CEP 13380-011, autor para correspondência e-mail: jackson@iz.sp.gov.br

${ }^{2}$ Médica Veterinária, Doutora pela Faculdade de Medicina Veterinária e Zootecnia - FMVZ da Universidade Estadual Paulista - UNESP “Júlio de Mesquita Filho” Distrito de Rubião Jr., s/n - Botucatu, SP, CEP 18618-970, Doutora pela Universidad de Salamanca, Espanha

${ }^{3}$ Médica Veterinária, Doutora pela Universidade Federal Rural de Pernambuco - UFRPE, Fiscal Estadual Agropecuário, Agência de Defesa e Fiscalização Agropecuário do Estado de Pernambuco, ADAGRO,

${ }^{4}$ Médico Veterinário, Mestrando da Faculdade de Medicina Veterinária e Zootecnia da Universidade Estadual Paulista "Júlio de Mesquita Filho” - Distrito de Rubião Jr., s/n - Botucatu/SP CEP 18618-970,

Resumo: Esta revisão tem o objetivo discutir sobre os principais pontos críticos do abate humanitário de bovinos com enfoques necessários para auditorias e fundamentalmente na elaboração de um laudo pericial. A produção brasileira de carne bovina tem grande importância no agronegócio, com destaque nacional e internacional. Nos últimos anos está cada vez mais crescente a preocupação da população com relação ao bem-estar dos animais de produção, fazendo valer o investimento na pesquisa científica e a educação humanitária em todos os segmentos das cadeias de produção. Nas décadas passadas o abate de animais de produção vinha sendo considerado um procedimento tecnológico de grau científico inferior, não compondo um assunto estudado por universidades, institutos de pesquisa e indústria. Posteriormente, este tema ganhou importância quando ficou evidente a influência da qualidade da carne e seus produtos no comércio nacional e internacional. Após as evidentes influências da Organização Mundial de Saúde Animal (OIE) e da Sociedade Humanitária Internacional (HSI) ganhou grande destaque pela demanda de produtos de origem de animais criados, manejados, transportados e abatidos através do uso de práticas humanitárias. Devendo-se considerar que bem-estar animal não corresponde obrigatoriamente em qualidade sanitária, mas sim uma preocupação ética e moral dos consumidores. O Ministério da Agricultura, Pecuária e Abastecimento no Brasil (MAPA) prevê que até 2020 a produção brasileira de carnes deverá fornecer $44,5 \%$ do mercado mundial, sendo este o grande desafio do Brasil para manter medidas efetivas de abate humanitário e liderar como exportador mundial de carnes bovina. Abater os animais em condições humanitárias é um dever moral do homem e cada país deve estabelecer regulamentos rígidos com objetivo de garantir esta condição para todas as espécies. Os métodos convencionais de abate de bovinos envolvem a operação de insensibilização prévia da realização da sangria, exceto os abates conduzidos de acordo com os rituais judaicos ou islâmicos. As ações das auditorias e a medicina veterinária legal têm importante contribuição no balizamento das questões judiciais e éticas neste processo. Para tanto, se torna necessário o investimento em estudos e discussões no aperfeiçoamento neste importante tema para utilização nas auditorias e na definição de um protocolo pericial direcionado ao abate humanitário.

Palavras-chave: abatedouro, bem-estar animal, bovinocultura, medicina veterinária forense, perícia 


\title{
Humanitarian slaughter and desensitization in cattle from the perspective of legal veterinary medicine: Review
}

\begin{abstract}
This review has the objective to discuss the main critical points of the humanitarian slaughter of bovines with approaches necessary for audits and fundaments for expert report. The Brazilian beef production has great importance in agribusiness, with national and international prominence. Currently, the population's concern about the welfare of production animals has been growing, making investments in scientific research and humanitarian education in all segments of the production chains. In the past decades the slaughter of production animals had been considered a technological procedure of inferior scientific grade, not composing a subject studied by universities, research institutes and industry. Subsequently, this issue gained importance when it was evident the influence of the quality of meat and its products in national and international trade. Following the obvious influences of the World Organization for Animal Health (OIE) and the International Humanitarian Society (HSI), the demand for source products of animals raised, handled, transported and slaughtered through the use of humanitarian practices grew up. It should be considered that animal welfare does not necessarily correspond to sanitary quality, but rather an ethical and moral concern of consumers. The Ministry of Agriculture, Livestock and Food Supply in Brazil (MAPA) predicts that until 2020 the Brazilian meat production will provide $44.5 \%$ of the world market, this being the great challenge of Brazil to maintain effective measures of humanitarian slaughter and to lead as a world exporter of bovine meat To slaughter animals under humanitarian conditions is a moral duty of man, and each country must establish strict regulations in order to guarantee this condition to all species. Conventional methods of slaughter of cattle involve the pre-desensitization of bleeding, except slaughtering conducted according to Jewish or Islamic rituals. The actions of audits and legal veterinary medicine have an important contribution in the settlement of judicial and etical issues in this process. So is necessary to invest in studies and discussions on the improvement of this important topic for use in audits and in the definition of an expert protocol aimed at humanized slaughter.
\end{abstract}

Key words: animal welfare, cattle breeding, expertise, slaughterhouse, veterinary forensic medicine

\section{Abate humanitario e insensibilización en bovinos desde la perspectiva de la medicina veterinaria legal: Revisión}

Resumen. Esta revisión tiene el objetivo de discutir sobre los principales puntos críticos del sacrificio humanitario de bovinos con enfoques necesarios para auditorías y fundamentalmente en la elaboración de un informe pericial. La producción brasileña de carne de vacuno tiene gran importancia para ganadería con destaque nacional e internacional. En los últimos años cada vez es más grande la preocupación con respecto al bienestar de los animales de producción, llevando a cabo la investigación científica y la educación humanitaria en todos los segmentos de las cadenas de producción animal. En las décadas anteriores el sacrificio de animales de producción era un procedimiento tecnológico de grado científico inferior, no componiendo un tema estudiado por universidades, institutos de investigación e industria. Posteriormente, este tema ganó importancia al ser evidente la influencia de la calidad de la carne y sus productos en el comercio nacional e internacional. Después de las evidentes influencias de la Organización Mundial de Salud Animal (OIE) y de la Sociedad Humanitaria Internacional (HSI), ha ganado gran importancia por la demanda de productos de origen de animales producido, manejados, transportados y abatidos a través del uso de prácticas humanitarias. Se debe considerar que el bienestar animal no corresponde solamente la calidad sanitaria, sino una preocupación ética y moral de los consumidores. El Ministerio de Agricultura, Pecuaria y Abastecimiento en Brasil (MAPA) prevé para 2020 la producción brasileña de carnes tendrá un 44,5\% del mercado mundial, siendo este el gran desafío de Brasil para mantener 
medidas efectivas de sacrificio humanitario y liderar como exportador mundial de carne de vacuno. Abate de los animales en condiciones humanitarias es un deber moral del hombre y cada país debe establecer reglamentos rigurosos con el objetivo de garantizar esta condición a todas las especies. Los métodos convencionales de sacrificio de bovinos involucran la operación de insensibilización previa de la realización del sangrado, excepto los sacrificios conducidos de acuerdo con los rituales judíos o islámicos. Las acciones de las auditorías y la medicina veterinaria legal tienen una importante contribución en el balizamiento de las cuestiones judiciales y éticas en este proceso. Por esto, es necesario el desarrollo y discusiones en el perfeccionamiento en este importante tema para su utilización en las auditorías y en la definición de un protocolo pericial dirigido al sacrificio humanitario.

Palabras clave: bienestar animal, bovinocultura, matadero, medicina veterinaria forense, pericia

\section{Introdução}

A cada dia cresce a preocupação dos consumidores com a forma como os animais são criados, transportados e abatidos, pressionado a indústria ao desafio de um novo paradigma: tratar com cuidados, respeitar a capacidade de sentir dos animais (senciência), melhorando não só a qualidade intrínseca dos produtos de origem animal, mas também a qualidade ética (Ludtke et al., 2012).

O abate de bovinos tem sido praticado há décadas; porém, os estudos científicos nestas áreas apenas tornaram-se importantes quando percebeu importância na qualidade da carne (Sobral et al., 2015). Todavia, as técnicas do abate humanitário dos animais destinados ao consumo humano vêm avançando mais no meio científico não somente pela influência na qualidade da carne, mas principalmente para evitar sofrimento desnecessário nas diversas etapas que antecedem o abate (Carlesci et al., 2014). Para tanto, todas as etapas da indústria de abate devem ser avaliadas sistematicamente, notadamente a insensibilização que é considerada o ponto crucial do abate humanitário (Roça, 2001). Neste contexto, a Justiça dos Estados, pelos Promotores e dos Procuradores da República requisitam os profissionais da Medicina Veterinária para condução de perícias em abatedouros para fiscalizar o cumprimento da Legislação (Castilho, 2000).

Neste contexto, quais os requisitos necessários para elaboração de um protocolo de perícia que possa ser aplicado no abate humanitário de bovinos? Este artigo tem o objetivo de descrever sobre as principais ações e procedimentos necessários para elaborar um protocolo de perícia aplicado no abate humanitário de bovinos na ótica da medicina veterinária legal, visando combater abates clandestinos, bem como aqueles que não se encontram dentro dos padrões técnicos definidos pela legislação.

\section{Desenvolvimento}

As ciências forenses constituem qualquer área de conhecimento utilizada para responder questionamentos jurídicos ou passíveis de utilização para fins legais. Estas ciências atuam no processo de formação e transferência de conhecimento científico e tecnológico em cada área das ciências naturais com objetivo de aplicar na análise de vestígios visando elucidar questões científicas de interesse da justiça. A aplicação dos princípios científicos é o suporte da criminalística, considerando que tudo por ela é investigado e avaliado com base das ciências forenses das diversas áreas de conhecimento (Velho et al., 2017).

A medicina veterinária legal é uma especialidade que utiliza conhecimentos médicos veterinários para esclarecimento de questões jurídicas e no Brasil ela está prevista na legislação pelo Decreto $\mathrm{n}^{\circ}$ 23.133, de 09 de setembro de 1933, o qual regulamentou a profissão do médico veterinário. Nessa ocasião, tal Decreto estabeleceu à função privativa do médico veterinário a realização de perícias em questões judiciais em que os animais são envolvidos, sendo a mesma ampliada e publicada na Lei ${ }^{\circ}$ 5.517, de 23 de outubro de 1968 (Castilho, 2017; Maiorka, 2012). Sendo assim, a peritagem em animais é uma das competências privativas do médico veterinário em casos de acidentes e questões judiciais (BRASIL, 1968). O procedimento técnico da perícia nos estabelecimentos de abate compõe-se de inspeção minuciosa de todas as situações que possam contribuir na elaboração do laudo, o qual retrata 
o resultado da perícia, de forma objetiva e clara que possibilite um leigo entender sem ambiguidades (Castilho, 2000).

A auditoria é uma análise realizada por um profissional com objetivo verificar procedimentos técnicos e tem como fundamento desvendar problemas específicos com vistas a correções e melhoria da gestão, podendo ser interna ou externa. $\mathrm{O}$ auditor pode ser responsabilizado por apresentar documentos falsos, ou por aquilo que não apurar corretamente. A auditoria pode constar em um processo, sendo documento utilizado para auxiliar o advogado a realizar uma petição inicial, ou mesmo servir como comprovação de fatos; porém, todos estes estão sujeitos ao exame pericial, caso a mesma seja solicitada pela autoridade judiciária ou policial. De acordo com Ludtke et al. (2010) as auditorias de bem-estar animal são trâmites que podem ser empregados para averiguar a atividade dos funcionários, equipamentos, instalações, manejo dos animais e ajustamento do abatedouro, conforme as exigências de mercados.

A perícia é sempre solicitada pela autoridade judiciária, está atrelada a processos civis ou criminais. O perito um profissional de nível superior, com expertise em determinada área técnica, é auxiliar do juiz, bem como um profissional que possui conhecimentos técnicos para responder quesitos das partes e dos mesmos, também conhecido como "longa manos" do juiz. Quando tratar-se de um processo penal, será nomeado um perito oficial, portador de diploma de curso superior e na ausência do mesmo o juiz poderá nomear duas pessoas idôneas, portadoras de diploma de curso superior, preferencialmente na área específica relacionada com a natureza do exame, conforme o Art.159 do Código do Processo Penal (CPP). No caso dos processos cíveis, os peritos serão nomeados entre os profissionais legalmente habilitados e os órgãos técnicos ou científicos devidamente inscritos no cadastro mantido pelo tribunal ao qual o juiz está vinculado, de acordo com o Art. 156 do Novo Código de Processo Civil (CPC). O perito indicado pelo juiz deve ser imparcial sendo o laudo pericial o documento produzido por ele. A perícia médico-veterinária pode ser beneficiada por laudos de peritos na área de expertise em bem-estar animal, notadamente quando apresentadas as decisões judiciais em casos de negligência e maus-tratos.

$\mathrm{O}$ avanço na ciência do bem-estar animal aguçou o senso crítico da necessidade de prevenção do sofrimento animal, adicionado ao olhar atento do consumidor, às boas práticas de produção e a preservação ambiental, desta forma, o bem estar animal agregou valor ao produto favorecendo a produtividade (Braga et al., 2018). Todos os animais sejam de companhia ou de produção, sujeitos a tutela humana estão expostos de forma permanente ou transitória às condições de crueldade, sendo a negligência a forma mais frequente e pouco estudada, que por sua vez torna o diagnóstico difícil pela falta de conhecimento técnico dos profissionais para lidar com esta questão (Garcia, 2017). No Brasil os crimes de maus-tratos contra animais são legalmente amparados principalmente pela Lei de Crimes Ambientais, no Artigo 32, previsto na Constituição Federal (Lei 9.605 de 12 de fevereiro de 1998). Este requisito torna-se de grande importância para as auditorias na indústria do abate, bem como para elaboração de projetos de políticas públicas oferecendo, assim, uma contribuição para incrementar o bem-estar animal, por meio de ações adequadas para redução dos crimes de maus-tratos.

A tecnologia de abate de bovinos destinada ao consumo humano vem sendo realizado há décadas, somente obteve maior atenção e importância científica quando se observou grande influência na qualidade da carne (Andrade et al., 2008; Civeira et al., 2006; Oliveira et al., 2008). A definição de qualidade geralmente tem relação com atributos intrínsecos da carne, entre eles a aparência, rendimento, palatabilidade, composição e segurança alimentar, embora esteja ocorrendo transformação neste conceito e alguns autores já incluem o bem-estar animal (Ludtke et al., 2012). As doenças transmitidas por alimentos (DTA) tem fundamental importância na questão da segurança alimentar e sua ocorrência representa um problema a saúde pública em decorrência de surtos de intoxicação e afetar a coletividade, apesar de muitas pessoas desconhecerem o assunto, ou até ignorar (Melo et al., 2018).

Temas relacionados ao bem-estar e abate humanitário vêm ganhando destaque na comunidade científica, indústrias e consumidores, não somente pela qualidade da carne, mas também para evitar sofrimentos desnecessários no processo de abate (Carlesci et al., 2014). O direito moderno tem interrelações muito próximas com diversas áreas científicas e tecnológicas, sendo os autores principais o juiz e a promotoria onde o perito faz a conexão entre o científico e o jurídico, sendo o perito veterinário o profissional graduado em medicina veterinária que tem o conhecimento de levar ao âmbito jurídico as 
análises e as interpretações fundamentadas na ciência animal, com objetivo de esclarecer a correta aplicação das leis (Santos-Filho \& Mayrink, 2017). A Fig.1 mostra as principais áreas de conhecimentos científicos e tecnológicos que têm inter-relações diretas ou indiretas com a indústria do abate.

No mundo atual a cada dia tem sido observada a crescente preocupação dos consumidores com a forma de como o homem trata, transporta e abate os animais para consumo, pressionando a pecuária e a indústria de alimentos de origem animal ao desafio de um novo paradigma. Decisões judiciais sobre caso de maus-tratos de animais podem ser amparadas por laudos de peritos em bem-estar animal. (Hammerschmidt \& Molento, 2014). De acordo com estes autores protocolos possibilitam a diferenciação do grau de bem-estar em escala compatível para os julgamentos na ocorrência de maustratos, facilitando as atividades dos profissionais envolvidos nestas investigações, favorecendo a redução de criminalidade. Estes autores utilizam os cinco graus de bem-estar descritos como: muito baixo, baixo, regular, alto e muito alto, graus de bem-estar baixo e muito baixo são considerados inaceitáveis e devem ser considerados como maus-tratos. Um protocolo de bem-estar animal pode ser considerado de grande relevância para análise de maus-tratos pelo fato do mesmo oferecer um método completo que finaliza no enquadramento possibilitando o diagnóstico ou não de maus-tratos, prontamente aplicável no meio judicial (Hammerschmidt \& Molento, 2017). Atualmente no Brasil o crime de maus-tratos está amparado, principalmente, pela Lei de Crimes Ambientais (Lei 9.605/1998). De acordo com esta Lei, no Artigo 32, constitui crime "praticar ato de abuso, maus-tratos, ferir ou mutilar animais silvestres, domésticos ou domesticados, nativos ou exóticos".

O abate tem sido considerado o ponto crítico do bem-estar animal (Gregory \& Shaw, 2000) e a insensibilização ou atordoamento é considerado a primeira etapa do abate (Roça, 2001). Quando a insensibilização não for realizada de forma eficiente a perda da consciência e a sensibilidade pode ser comprometida o que acarreta alto grau de sofrimento (Ludtke et al., 2012). Não obstante, o abate humanitário deve ser conduzido sem sofrimentos desnecessários e as condições humanitárias devem prevalecer tanto no momento do abate quanto em todas as etapas precedentes ao mesmo, constituindo um dever moral a proteção humanitária aos animais (Roça, 2001).

\section{Equipe operacional}

O manejo dos animais no abatedouro e frigorífico tem fundamental importância na segurança dos operadores e dos animais (Cortesi, 1994; Roça, 2001). Para que o manejo seja adequado e eficaz é fundamental conhecer o comportamento dos bovinos para reconhecer sinais de estresse e dor. Assim como, deve-se também conhecer as relações dos bovinos com o ambiente de produção e suas necessidades, para poder proporcionar, nas instalações e no manejo, os recursos que promovam melhorias no bem-estar dos animais (Ludtke et al., 2012).

As necessidades de segurança dizem respeito a acidentes com equipamentos e instalações, ação de predadores, entre outros, que em geral são pouco considerados, provavelmente pelo fato de não serem alvo de muitos estudos, mas que podem resultar até em morte do animal. Dentre todas, as necessidades comportamentais são as menos compreendidas, sendo classificadas em três categorias: abuso (crueldade ativa, agressão física), negligência (crueldade passiva do tipo que ocorre quando um animal é confinado e então é negada uma necessidade fisiológica como alimento, água, cuidados com a saúde ou abrigo) e privação (crueldade passiva que envolve a negação de certos elementos ambientais que são considerados menos vitais que as necessidades fisiológicas ou de segurança (Dawkins, 2017; Llonch et al., 2015). O não atendimento dessas necessidades geralmente resulta em frustração, medo ou desconforto, com consequências negativas no processo produtivo como um todo, com queda na produtividade e produtos de pior qualidade (Campo et al., 2014; Koknaroglu \& Akunal, 2013).

A equipe operacional do frigorífico está composta principalmente pelo gerente de produção e demais funcionários comprometidos em seguir todo regulamento das normas técnicas operacionais estabelecidas pela legislação pertinente para assegurar o bem-estar animal. Para tanto, torna-se necessário que toda equipe seja treinada, capacitada e comprometida com todas as etapas do processo do abate, formando um elo harmonioso entre pessoas, instalações e equipamentos (Ludtke et al., 2012). Os assistentes operacionais responsáveis pelo manejo dos animais de abate devem estar comprometidos com a legislação, seguindo as normas técnicas para garantir o bem-estar animal. Para auxiliar e garantir as auditorias, Grandin (2014) desenvolveu pontos críticos de controle de bem-estar animal com seus limites de tolerância. Entre estes 
pontos a autora destaca: a densidade e o transporte dos animais; densidades dos currais de descanso; condições dos pisos para evitar escorregões e quedas; disponibilidade de água; tempo de jejum e descanso; uso do bastão elétrico para induzir deslocamento dos animais; avaliação da vocalização e eficiência na insensibilização. Cabe às auditorias monitorar toda operação de abate, notadamente no que diz respeito ao desempenho dos funcionários e a eficiência dos equipamentos, bem como a manutenção e melhoria das instalações e o manejo dos animais (Ludtke et al., 2012).

\section{Áreas físicas de investigação}

Tem sido observado que nos últimos anos melhorias nas estruturas dos abatedouros incorporando novas tecnologias para obter maior eficiência no processo de abate, no entanto, muitas destas estruturas planejadas não atendem as necessidades comportamento dos animais, tampouco o bem-estar animal, exigência cada vez maior dos consumidores em relação à qualidade e procedência aos produtos de origem animal. Nos estabelecimentos de abate o perito deve levar em consideração as áreas externa e internas, sendo que nas externas são inspecionados a delimitação, pavimentações, contaminações do ambiente, integridades dos currais e estruturas anexas, seringas, banheiros, equipamentos de contenção, insensibilização e box de atordoamento, enquanto que nas áreas internas são inspecionados a higiene, as instalações, os equipamentos e as condições sanitárias necessárias para o abate (Castilho, 2000). No caso das instalações estes autores destacam o complexo físico da construção civil, incluindo sala de abate, currais e estruturas anexas, sistemas de água e esgoto, vapor e eletricidade, assim o perito finaliza o laudo com assinatura, data e número do Registro do Conselho Regional de Medicina Veterinária a que pertence, podendo o mesmo se deparar com graves comprometimentos que possam afetar o bem-estar animal, o abate humanitário e a saúde pública. Para tanto, faz-se necessário que o perito tenha o domínio da legislação vigente, condição necessária para o mesmo desempenhar seu papel na proteção animal e na saúde pública.

\section{Corredores de passagens, seringas e deslocamento dos animais}

Os bovinos são estimulados a deslocar quando visualizam outros animais em movimentos, assim, para o deslocamento adequado torna-se necessário que os corredores sejam bem dimensionados proporcionando as movimentações em lotes (Ludtke et al., 2012). De acordo com estes autores corredores inadequados, muito estreitos e construídos com mudanças de direção em ângulos fechados, escuros e muito longos pode dificultar o manejo dos bovinos. Em todas estas estruturas os pisos devem ser antiderrapantes para promover os deslocamentos dos animais com segurança e evitar escorregões, lesões e quedas (Ludtke et al., 2012). Estes autores destacam a importância de estruturas das paredes e dos pisos, os quais promovem segurança aos animais para seguirem o fluxo de movimentação, as alterações nestas estruturas podem induzir deslocamentos lentos, ou relutância a caminhar, o que pode ser complicado pela presença de reflexos e contrastes de luzes, poças d'água, buracos, alterações da superfície de texturas dos pisos, degraus, ralos ou calhas (Ludtke et al., 2012). Os corredores são estruturas largas que conduzem animais em grupos, as seringas são estreitas e que têm a finalidade de conduzir os animais individualmente, que destina a linha do abate e que estressa os bovinos devido ao isolamento social, sendo considerado um ponto crítico do bem-estar animal (Ludtke et al., 2012). Segundo estes autores as seringas são classificadas de acordo com a ordem crescente de facilidade de manejo e bem-estar em: retangulares, semicircular e circular, pelo fato das últimas transmitirem a impressão de que os animais estão "retornando" a direção inicial. Para impedir o retorno dos animais ou resistência para entrada no brete as seringas dispõem de porteiras vazadas para que os animais visualizem o campo a seguir e permitir que eles avancem cada vez mais em direção ao de atordoamento, para tanto, é imprescindível uma sincronia de atividades entre animais e manejadores para permitir o fluxo constante de animais na linha de abate. Qualquer erro estrutural pode afetar o bem-estar dos animais, entre eles bretes muito curtos, curvas acentuadas ou muito estreitas. Portanto, pode haver falha estrutural, mecânica ou humana nesse processo e contribuir com problemas de bem-estar animal ou humano (Ludtke et al., 2012).

\section{Transporte dos animais}

Durante o transporte, o esforço físico proporcionado por condições desfavoráveis, tais como agrupamento em currais, privação de alimento, alta umidade, densidade de transporte, embarque e 
desembarques inadequados e estresse psicológico aumentam o risco da ocorrência de cortes escuros da carne. Além disso, as condições de transporte, tipo caminhão e design da carroceria, densidade, condições climáticas, tempo de transporte, distância, treinamentos dos funcionários, condições da estrada, comportamento animal, sexo e raça, podem interferir no nível de bem-estar de bovinos (Schrama et al., 1996; Strappini et al., 2009). Embora não esteja relacionado diretamente com o abatedouro frigorífico o transporte dos animais deve ser investigado, notadamente quando este finaliza nos desembarcadores destes estabelecimentos.

O estresse dos animais destinados ao abate inicia no momento do embarque, pelo abandono do local em que viviam e estavam habituados. No processo de transporte a responsabilidade pelo bem-estar dos animais é do expedidor para reunir e embarcar os animais, além da preparação, incluindo a inspeção e seleção, como, "apto para a viagem pretendida", fornecimento de ração e água, assegurando os períodos ideais de jejum. O transportador é responsável pelo carregamento, densidade da carga, inspeções durante o transporte, tempo das paradas no período da viagem e descarregamento. O receptor no desembarque dos animais é responsável pela inspeção e registros de quaisquer anotações referentes ao bem-estar dos mesmos. Além disso, observar as condições dos veículos para minimizar riscos de lesões, escorregamentos ou quedas (Nielsen et al., 2011; Schwartzkopf-Genswein et al., 2012).

Do ponto de vista de bem-estar e saúde pública os animais que estejam incapacitados de andar por conta própria, não suportar o próprio peso, severamente magros, visivelmente desidratados, evidências de lesões graves, angustiados, afetados por doenças, dor ou sofrimento, não devem ser transportados e caso algum destas condições sejam evidenciadas no desembarque devem ser manejados cuidadosamente com assistência médico veterinária, para julgar a necessidade de abate de emergência. A utilização de bastões elétricos no manejo de embarque desencadeia agitação e estresse, o que pode aumentar os riscos de acidentes com os animais, sendo aconselhável a substituição por bandeiras para promover os deslocamentos dos animais de forma mais humanitária (Ludtke et al., 2012).

No momento do embarque quando na ocorrência de acidentes com lesões graves em que o animal não pode se locomover, apresentando sinais de dor e sofrimento intenso ou agonizante a eutanásia tornase inevitável (Ludtke et al., 2012), seguindo assim, as recomendações dos procedimentos do Conselho Federal de Medicina Veterinária (Brasil, 2012, Resolução CFMV, n. 1000). No Art. $2^{\circ}$ para fins desta Resolução, eutanásia é a indução da cessação da vida animal, por meio de método tecnicamente aceitável e cientificamente comprovado, observando os princípios éticos aqui definidos em outros atos do CFMV. No Art. 15. De acordo com o Cap. III, Art. 16. A não observância das regras e princípios definidos nesta Resolução sujeitará o médico veterinário a responder processo ético profissional.

\section{Desembarcador de animais e currais de espera}

Os animais deverão ser desembarcados logo na chegada ao frigorífico e os currais de espera devem oferecer um ambiente tranquilo onde os animais possam descansar sem interferência de trânsito de funcionários que possam causar estresse (Ludtke et al., 2012). Estes currais têm que ser projetados em função do número de animais destinados ao abate, evitar acidentes com pessoas e animais e facilitar o manejo necessitando ainda ter livre acesso à água limpa e abundante e, caso sejam mantidos por mais de 24 horas, devem ser alimentados em quantidades moderadas em intervalos adequados. Os pisos precisam ser impermeáveis, de fácil higienização e drenagem, de superfície plana, com antiderrapantes apenas no raio das porteiras, íntegro, sem frestas para evitar acidentes nos animais (BRASIL, 2000). Não se recomenda o planejamento de currais para alojar um grande número de animais para evitar aglomeração de diferentes faixas etárias, ocorrências de brigas e quebra de hierarquia social (Ludtke et al., 2012).

\section{Box de insensibilização ou atordoamento}

A contenção é aplicação de um determinado meio físico a um animal, ou qualquer processo destinado a limitar seus movimentos, para uma insensibilização eficaz (BRASIL, 2000)Para realização de uma insensibilização eficiente torna-se necessário que o animal seja contido da melhor forma possível, de forma que o disparo ocorra na posição correta no box de atordoamento, os quais podem ser preferencialmente metálico, mecânico ou automatizado, com ou sem contenção da cabeça (Sobral et al., 2015). O box que possui bandeja de contenção da cabeça promove melhoria no bem-estar pelo fato do mesmo possibilitar a limitação dos movimentos da cabeça, o que facilitar o disparo com precisão. Os 
animais não serão alocados no box de atordoamento se o responsável pela operação não poder proceder essa ação imediatamente após a introdução do animal neste recinto BRASIL, 2000. No box de atordoamento o bovino é isolado dos demais do lote e contido numa estrutura que limita o máximo possível os movimentos para realização segura da insensibilização com pistola de dado cativo. A estrutura do box de atordoamento tem fundamental importância na indústria do abate, uma vez que quando este apresentar inadequações em suas estruturas ou falta de manutenção pode causar riscos fatais de acidentes com os animais ou com os operadores (Ludtke et al., 2012). Entre estas falhas os autores citam a configuração de boxes muito grande o qual permitem movimentação do animal no seu interior, aumentando os riscos de acidentes, existindo ainda ruídos nas portas de fechamento e sala de abate e iluminação inadequada, fatores estes que contribuem para que os animais resistam entrar no box, sendo necessário a utilização do bastão elétrico como medida para induzir a movimentação dos animais para dentro do box. Quando é necessária a utilização de bastão elétrico para induzir a movimentação dos animais indica que o manejo está inadequado, notadamente quando este bastão é tocado nas regiões sensíveis dos animais, como olhos, mucosas e orelhas (Roça, 2001). Há situações em que o uso do bastão nunca deve ser utilizado, com exemplo, nos casos em que o animal não reage tampouco ligar diretamente na alta voltagem, causando estímulos elétricos extremamente dolorosos (Ludtke et al., 2012).

De acordo com a Instrução Normativa da Secretaria de Defesa Agropecuária - SDA, de 17 de fevereiro de 2000 os bastões elétricos apenas poderão ser utilizados em caráter excepcional, nos animais que se recusem mover, desde que essas descargas não durem mais de dois segundos e haja espaço suficiente para que os animais avancem BRASIL, 2000. Nesta Instrução contempla ainda que não será permitido espancar os animais ou agredi-los, erguê-los pelas patas, chifres, pêlos, orelhas ou caudas, ocasionando dores ou sofrimento.

\section{Insensibilização}

A insensibilização ou atordoamento é um procedimento técnico-científico realizado para promover o estado de inconsciência e insensibilidade em animais de produção, sem causar-lhes medo, ansiedade, angústia, dor e sofrimento (Gregory \& Grandin, 2007). Os métodos de insensibilização progrediram consideravelmente ao longo da história de abate dos bovinos. Em concordância com o bem-estar animal os abatedouros frigoríficos evoluíram nos últimos anos com introdução de novas tecnologias de equipamentos com objetivo de alcançar qualidade na produção (Carlesci et al., 2014; Sobral et al., 2015). Do ponto de vista de bem-estar o abate tem sido considerado um procedimento de grande importância que utiliza métodos técnicos científicos para colocar o animal em estado de inconsciência que perdure até a sangria completa, não causando sofrimento desnecessário (Andrade et al., 2008; Roça, 2001). Neste contexto, para evitar dor e sofrimento desnecessários deve prevalecer condições humanitárias em todos os procedimentos realizados no abate. Para uma insensibilização eficiente é necessário que o animal seja contido da melhor forma possível para que o disparo seja realizado na posição correta (Gallo et al., 2003). A insensibilização dos bovinos está regulamentada de acordo com a Instrução Normativa n. 3, de 17 de janeiro de 2000 do Ministério da Agricultura Pecuária e Abastecimento (BRASIL, 2000).O abate humanitário pode ser conceituado como um conjunto de procedimentos técnicos que garantem o bem-estar dos animais desde o embarque no ambiente rural da propriedade até o momento da sua morte no frigorífico, quando não realizado conforme a legislação vigente o abate humanitário pode ser considerado como maus-tratos (Santos-Filho \& Mayrink, 2017).

O abate de emergência deve ser conduzido o mais rápido possível para evitar dor e sofrimentos desnecessários (Ludtke et al., 2012). A manutenção das pistolas de dardos cativos com penetração pode ter influência na insensibilização e bem-estar animal. No trabalho de Andrade et al. (2008) verificou-se diferença entre o dia de abate e o número de disparos, resultado com maior número de disparos foi relacionado com a falta de limpeza do dardo cativo de penetração, apresentando corrosões por oxidação metálica no êmbolo da pistola, comprometendo o funcionamento adequado, o que pode provocar maior sofrimento animal, maior esforço físico e menor segurança aos operadores.

\section{Insensibilização por dardos cativos}

Os dardos cativos podem ser penetrantes e não penetrantes e quanto à energia necessária para propulsar o dardo pode ser obtida por cartucho de explosão (festim) ou por ar comprimido, pistolas 
pneumáticas (Ludtke et al., 2012). Os dardos cativos penetrantes e não penetrantes são os mais utilizados nos abatedouros por promoverem estado de inconsciência com muita rapidez (Finnie et al., 2000). A insensibilização por dardos cativos, com ou sem pistolas de penetração pode causar falhas de manutenção dos equipamentos, fadiga nos operadores defeitos no desenho ergonômico dos equipamentos (Grandin, 1998). O método de insensibilização mais empregado para abater bovinos nos matadouros frigoríficos do Brasil é realizado com pistola pneumática de penetração e quando procedido de forma adequada promove uma perfuração do crânio e laceração encefálica, levando a rápida inconsciência do animal (Carlesci et al., 2014). A posição do disparo na cabeça do animal é de fundamental importância para promover uma insensibilização eficiente. Para a insensibilização com dardo cativo penetrante seja realizada de forma adequada é necessário que este efetue um golpe no ponto exato do crânio, na região mais delgado do osso frontal, ou seja, onde se cruzam as duas linhas imaginárias definidas entre a base do corno até o olho oposto (Gallo et al., 2003; Ludtke et al., 2012). Para tanto, é necessário que a pistola seja posicionada perpendicular e em contato a cabeça do animal, formando um ângulo de 90 graus e no caso do dardo cativo não penetrante o disparo é realizado dois centímetros acima da linha de cruzamentos, sendo necessário também o correto posicionamento para atingir o alvo com precisão. $\mathrm{O}$ impacto causado pelo dardo cativo tem a finalidade de promover concussão cerebral que leva a perda imediata da consciência, a qual impede a transdução do estímulo da dor. Nesta posição o dardo será penetrado no crânio, atingindo o córtex cerebral, tronco cerebral e cerebelo que são as principais estruturas cerebrais responsáveis pela inconsciência (Ludtke et al., 2012). A insensibilização com dardo cativo de penetração causa forte impacto no cérebro levando a disfunção da atividade elétrica devido a grave alteração de pressão, geralmente não ocorrendo fratura do crânio, mas sim apenas uma perfuração (Bertoloni \& Andreolla, 2010). Na Inglaterra e outros países é obrigatório que a insensibilização com dardo cativo seja realizada com a imobilização da cabeça para facilitar que o disparo seja realizado no ponto exato (Bertoloni \& Andreolla, 2010). Apesar deste tipo de contenção oferecer maior segurança para o operador efetuar o disparo na posição correta, pode ocasionar estresse no animal em casos de contenção errada e demorada (Grandin, 1985).

Entre todos os métodos disponíveis o uso da pistola pneumática de penetração e a pistola de dardo cativo acionada por cartucho de explosão são os mais eficientes por promover inconsciência imediata durante a sangria, o que evita menos estresse e sofrimento animal (Sobral et al., 2015). Entretanto, a qualquer fator que comprometa a velocidade do dardo, seja por manutenção inadequada ou outros fatores, pode afetar a eficiência da insensibilização, na prática existem diversos fatores que interferem significativamente na eficácia e tempo de duração da insensibilização, como falhas do equipamento, contenção inadequada, treinamento e capacitação do operador, por estes e outros fatores as legislações exigem que a sangria seja efetuada sem demora, até 60 segundos após o primeiro disparo, sendo assim, torna-se imprescindível o monitoramento frequente da insensibilização de todos os animais durante o abate (Ludtke et al., 2012). Tanto na insensibilização por dado cativo com pistola de penetração ou sem penetração as principais causas de fracassos no atordoamento são a falta de manutenção dos equipamentos, cansaço do operador, equipamentos inadequados, o que contribui para erros técnicos no disparo na cabeça do animal (Grandin, 1998). Para um atordoamento eficiente é necessário também que o posicionamento e a angulação da pistola em contato com o crânio do animal possibilite que o dardo atinja o córtex cerebral, o tronco encefálico e cerebelo, as quais são as principais estruturas responsáveis para levar o animal ao estado de inconsciência (Finnie, 1993). Deve-se levar em consideração que a efetividade da insensibilização depende ainda da categoria do animal, assim, animais velhos e os touros são mais difíceis de ser atordoado que as outras categorias, para estes devem-se dar preferência o uso de pistolas de penetração, de forma semelhante não é recomendado o uso de pistolas não penetrantes em bovinos com menos de oito meses de idade, devido ao fato desses animais ainda ter crânio pouco rígido. Os bovinos insensibilizados de forma eficiente não vocalizam, não exibem reflexo palpebral ou corneal, apresentam mandíbula relaxada e com língua exposta, membros torácicos retos e membros pélvicos podem apresentar movimentos de pedalagem não coordenados (Ludtke et al., 2012). A eficiência da insensibilização pode ser afetada por agravantes como falta de manutenção dos equipamentos, falta de mão-de-obra qualificada dos funcionários e estresse dos animais (Sobral et al., 2015). 


\section{Área de vômito, suspensão e sangria}

Ao finalizar a insensibilização o bovino desliza sobre a grade tubular da área de vômito e antes de ser içado o animal deve estar em estado de inconsciência para evitar estresse, dor e sofrimento desnecessário (Grandin, 2013; Roça, 2001). Todo bovino deve estar inconsciente antes da sangria e deve permanecer neste estado até que ocorra a morte, é necessário que antes da seja avaliada as ausências de sinais de sensibilidade e quando houver dúvidas a insensibilização deve ser repetida. Nenhum animal deve ser içado ou sangrado estando sensíveis, os animais devem estar inconscientes durante a sangria e permanecer nesse estado até a morte, para tanto, se torna necessário que o funcionário responsável por esta avaliação seja comprometido com esta função, pois falhas nesse processo acarreta grande sofrimento aos animais (Ludtke et al., 2012). Os sinais de insensibilização devem ser avaliados na canaleta de sangria, entre estes sinais destacam-se a vocalização, movimentos e reflexos oculares e contração dos membros dianteiros (Roça, 2001).

$\mathrm{Na}$ calha de sangria dever observar sinais como protrusão da língua, o qual é um indicador de relaxamento dos músculos masseter, ausência de respiração rítmica, bem como ausência de reflexos de dores que são avaliados notadamente na narina e língua (Barbosa Filho \& Silva, 2004; Mendonça \& Caetano, 2017). Para este autor o reflexo de córnea é o mais notável indicador de sensibilidade. A ocorrência de animais sensíveis na calha de sangria indica falhas graves em auditorias de bem-estar animal, havendo tolerância máxima de apenas dois animais a cada 1000 avaliados e na ocorrência desta falha deve-se realizar imediatamente outra insensibilização com pistolas de dardo cativo portátil (Barbosa Filho \& Silva, 2004; Mendonça \& Caetano, 2017). O processo de sangria é realizado na calha de sangria em até um minuto após a insensibilização do animal e deve provocar o mais rápido e profuso escoamento do sangue, antes que o animal retorne a insensibilidade, não sendo permitidas quaisquer operações de mutilações, até o máximo escoamento do sangue BRASIL, 2000). A sangria é realizada inicialmente pelo corte sagital da barbela e pela seção dos grandes vasos do pescoço atingindo aorta, veia cava, artérias carótidas e veias jugulares (Mendonça \& Caetano, 2017).

Para auxiliar a avaliação do bem-estar animal e de inconformidades no sistema de abate humanitário o perito pode graduar, de acordo com o grau de importância de cada item, os principais pontos críticos para elaboração de um protocolo pericial no abate de bovinos (PCPP), em três pontos: adequado, regular e inadequado, de acordo com o exame de corpo de delito realizado por legistas. Entre os principais fatores envolvidos no sistema de abate humanitário destacam-se: manejo geral bastão elétrico (evitar nas regiões sensíveis como olhos, orelhas, focinho, ânus, cauda e genitais) e utilizar apenas nas áreas críticas como último recurso antes do box de atordoamento; seringas; tempo de jejum de descanso; transporte; condições dos veículos; capacitação dos motoristas; carteira especial para motoristas de transporte de carga viva; fiscalizações das condições dos veículos; identificação dos veículos de transporte de cargas vivas; manejo do transporte (inadequado); tipo de transporte (pé, rodoviário, ferroviário, marítimo e aéreo); densidade do transporte (evitar superlotação; peso médio dos bovinos; veículo bem estacionado para evitar vãos entre compartimentos; desembarque rápido, não passar de 1 hora); bastão elétrico; condições do peso do veículo (evitar escorregões e quedas); desembarcadores (Estrutura física e segurança); currais de espera (estrutura, comedouros, bebedouros, alimentação, densidade, tempo de jejum); disponibilidade de água; corredores e seringas (estrutura física); banhos; box de atordoamento; operador da insensibilização (falta de mão-de-obra qualificada, estado psicológico); insensibilização; insensibilização por dardo cativo de penetração; insensibilização por dardo cativo de não penetração; insensibilização por dardo cativo de penetração com injeção de ar; indicadores de consciência e inconsciência; eficiência nos disparos; pistola portátil; postura em pé; reflexo de endireitamento; vocalização (áreas onde ocorre: contenção, insensibilização, bastão elétrico, falhas no atordoamento, escorregões, quedas, pressões excessivas na contenção); piscar de olhos espontaneamente; movimentos de perseguição ocular; resposta ao teste de ameaça; ausência de respiração rítmica; ausência de reflexo ocular; área de vômito (estrutura física); avaliação da insensibilização, suspenção (estrutura física); sangria; avaliação da insensibilização antes da sangria e tempo mínimo para realização da sangria. 


\begin{tabular}{|c|c|c|}
\hline Manutenção Equipamentos & Manutenção Instalações & Manejo Humanitário \\
\hline Manutenção Edificações & Bem-estar Animal & Iluminação \\
\hline & & \\
\hline Legislação Animal & Bem-estar Humano & Medicina Veterinária Legal \\
\hline & & 足 \\
\hline Comportamento Animal & Etologia Clínica & Trans porte Animal \\
\hline & & L \\
\hline Engenharia Elétrica & ABATE HUMANITÁRIO & Engenharia Ambiental \\
\hline Engenharia Mecânica & Legislação Ambiental & Biossegurança \\
\hline & & \\
\hline Bioética & Saúde Animal & Saúde Humana \\
\hline & & +1 \\
\hline Fiscalização & Coaching Funcionários & Pesquisa Científica \\
\hline & & \\
\hline Disciplina & Treinamentos & Inspeção Veterinária \\
\hline
\end{tabular}

Figura 1. Inter-relação das áreas técnico e científicas de conhecimento relacionadas com a indústria de abate, considerando a importância dos princípios e fundamentos da medicina veterinária legal, bem-estar e biossegurança.

\section{Discussão}

A preocupação com o bem-estar animal, notadamente no que diz respeito ao abate vem crescendo, tanto na visão social quanto na política, religiosa, ética, legislativa e científica. Ao longo dos anos percebe-se que a indústria de abate de bovinos vem evoluindo juntamente com a ciência do bem-estar animal, sendo atualmente aperfeiçoada com o surgimento de novas legislações. No Brasil já existe há décadas uma legislação que mantém a obrigatoriedade de conduzir a indústria da matança nas condições de bem-estar de forma a que permite penalidades aos estabelecimentos que infringi-la. Quando o abate não está de acordo com esta legislação pode ser considerado tecnicamente como maus-tratos, entretanto, esta legislação faz ressalvas nos abates destinados às comunidades religiosas. Como ciência de suporte a esta legislação e ao aperfeiçoamento da mesma surge no Brasil, nos últimos anos, o avanço no conhecimento da medicina veterinária legal como ciência fundamental para balizar a indústria do abate embasada nos princípios do bem-estar e da justiça. Diante deste contexto legal a atuação dos médicos veterinários na condição de perito tem fundamental importância como auxiliares da justiça nos processos judiciais relacionados à indústria do abate, notadamente no que diz respeito ao abate humanitário. Com isto, este tema tem sido tratado por diversos seguimentos da sociedade, pondo o poder público e a coletividade o dever defender bem-estar dos animais de produção, aperfeiçoar os mecanismos tecnológicos de proteção que levem os animais a um manejo pré-abate e abate em condições mais humanitárias possíveis para garantir o Brasil no quadro dos maiores produtores e exportadores de carne bovina com qualidade sanitária e ética.

\section{Conclusão}

Como visão multidisciplinar e valioso conteúdo as ciências forenses, fornece as bases fundamentais para a medicina veterinária legal a qual se utiliza das principais áreas de criminologia, criminalística e perícia modernas para dar suporte à indústria do abate. A indústria do abate precisa de regras especiais para minimizar a dor e o sofrimento dos animais. Neste contexto, a medicina veterinária legal oferece conhecimento da realidade da ciência e da neurociência do abate com base na investigação, objetivando a descoberta da verdade e, consequentemente, na tomada de decisões técnica e científicas na resolução das questões criminais. Estes conhecimentos auxiliam na análise de elementos para elaboração de laudos periciais de interesse da justiça para responder aos preceitos gerais. 


\section{Referências bibliográficas}

Andrade, E. N., Silva, R. A. M. S., Roça, R. O., Silva, L. A. C., Gonçalves, H. C. \& Pinheiro, R. S. B. (2008). Ocorrência de lesões em carcaças de bovinos de corte no Pantanal em função do transporte. Ciência Rural, 38(7):1991-1996.

Barbosa Filho, J. A. D. \& Silva, I. J. O. (2004). Abate humanitário: ponto fundamental do bem-estar animal. Revista Nacional da Carne, 32836-44.

Bertoloni, W. \& Andreolla, D. (2010). Eficácia do sistema de contenção (automatizado e mecânico) no atordoamento de bovinos. Ciência Rural, 40(8):1-7.

Braga, J. S., Macitelli, F., Lima, V. A. \& Diesel, T. (2018). O modelo dos "Cinco Domínios" do bemestar animal aplicado em sistemas intensivos de produção de bovinos, suínos e aves. Revista Brasileira de Zoociências, 19(2):204-226.

BRASIL, Lei de Crimes Ambientais, 9.605 de 12 de fevereiro de 1998. Dispõe sobre as sanções penais e administrativas derivadas de condutas e atividades lesivas ao meio ambiente, e dá outras providências. Diário Oficial da União de 13 de fevereiro de 1998. http://www.planalto.gov.br/ccivil_03/leis/L9605.htm [Acesso 22 de Jan de 2018].

BRASIL, Lei n. 5.517, de 23 de outubro de 1968, Art. $5^{\circ}$. Estabelece competência legal privativa para o médico veterinário realizar peritagem em animais em exames técnicos e questões judiciais, entre outras competências. [Acesso em 05 de março de 2018]. http://www.planalto.gov.br/ccivil_03/leis/L5517.htm

BRASIL, Lei n. 5.517, de 23 de outubro de 1968. Resolução n. 1000, de 11 de maio de 2012. Dispõe sobre procedimentos e métodos de eutanásia em animais e dá outras providências. [Acesso em 27 de setembro de 2018].

BRASIL, Ministério da Agricultura, Pecuária e Abastecimento. Divisão de Normas Técnicas. Instrução Normativa n. 3, de 17 de janeiro de 2000. Aprova o Regulamento Técnico de Métodos de Insensibilização para o Abate Humanitário de Animais de Açougue. Diário Oficial da União, Brasília, 24 jan. 2000. Seção I, p. 14-16, 2000.

Campo, M. M., Brito, G., Montossi, F., Soares de Lima, J. \& San Julián, R. (2014). Animal welfare and meat quality: The perspective of Uruguay, a "small" exporter country. Meat science, 98470-476.

Carlesci, R. H., Bürger, K. P., Rossi, G. A. M., Saba, R. Z., Vidal-Martins, A. M. C. \& Gonzalez, P. O. (2014). Eficácia da insensibilização em bovinos pelo uso de pistola pneumática de penetração em matadouro-frigorífico no Estado de São Paulo, Brasil. Revista Brasileira de Higiene e Sanidade Animal, 8(1):73-80.

Castilho, V. C. (2017). Atuação do perito em medicina veterinária. In R. A. Tostes, S. T. J. Reis \& V. V. Castilho (Eds.), Tratado de Medicina Veterinária Legal. Curitiba, Paraná, Brasil. : Medvep.

Castilho, V. V. (2000). Perícia em estabelecimentos de abate. Revista de Educação Continuada em Medicina Veterinária e Zootecnia do CRMV-SP, 3(3):65-70.

Civeira, M. P., Renner, R. M., Vargas, R. E. S. \& Rodrigues, N. C. (2006). Avaliação do bem-estar animal em bovinos abatidos para consumo em frigorífico do Rio Grande do Sul. Revista Veterinária em Foco, 4(1):5-11.

Cortesi, M. L. (1994). Slaughterhouses and humane treatment. Revue Scientifique et Tecnnique Office International des Epizooties, 13(1):171-193.

Dawkins, M. S. (2017). Animal welfare and efficient farming: is conflict inevitable? Animal Production Science, 57(2):201-208.

Finnie, J. W. (1993). Brain damage caused by a captive bolt pistol. Journal of Comparative Pathology, 109(3):253-258.

Finnie, J. W., Blumbergs, P. C., Manavis, J., Summersides, G. E. \& Davies, R. A. (2000). Evaluation of brain damage resulting from penetrating and non-penetrating captive bolt stunning using lambs. Australian Veterinary Journal, 78(11):775-778. 
Gallo, C., Teuber, C., Cartes, M., Uribe, H. \& Grandin, T. (2003). Mejoras en la insensibilización de bovinos con pistola neumática de proyectil retenido tras cambios de equipamiento y capacitación del personal. Archivos de Medicina Veterinaria, 35(2):159-170.

Garcia, R. C. M. (2017). Desafios para o enfrentamento da negligência. In R. A. Tostes, S. T. J. Reis \& V. V. Castilho (Eds.), Tratado de medicina veterinária legal. Curitiba, Paraná: Medvep.

Grandin, T. (1985). Race system for cattle slaughter plants with 1.5-m radius curves. Applied Animal Behaviour Science, 13(3):295-299.

Grandin, T. (1998). The feasibility of using vocalization scoring as an indicator of poor welfare during cattle slaughter. Applied Animal Behaviour Science, 56(2-4):121-128.

Grandin, T. (2013). Making slaughterhouses more humane for cattle, pigs, and sheep. Animal Review of Animal Bioscienses, 1(1):491-512.

Grandin, T. (2014). Animal welfare and society concerns finding the missing link. Meat Science, 98461 469.

Gregory, N. \& Shaw, F. (2000). Penetrating captive bolt stunning and exsanguination of cattle in abattoirs. Journal of Applied Animal Welfare Science, 3(3):215-230.

Gregory, N. G. \& Grandin, T. (2007). Animal welfare and the meat market. Cambridge: CABI.

Hammerschmidt, J. \& Molento, C. F. M. (2014). Protocol for expert report on animal welfare in case of companion animal cruelty suspicion. Brazilian Journal of Veterinary Research and Animal Science, 51(4):282-296.

Hammerschmidt, J. \& Molento, C. F. M. (2017). Perícia em bem-estar animal nos crimes de maus-tratos contra animais. In R. A. Tostes, S. T. J. Reis \& V. V. Castilho (Eds.). Tratado de Medicina Veterinária Legal. Curitiba, Paraná, Brasil: Medvet.

Koknaroglu, H. \& Akunal, T. (2013). Animal welfare: An animal science approach. Meat Science, 95(4):821-827.

Llonch, P., King, E. M., Clarke, K. A., Downes, J. M. \& Green, L. E. (2015). A systematic review of animal based indicators of sheep welfare on farm, at market and during transport, and qualitative appraisal of their validity and feasibility for use in UK abattoirs. The Veterinary Journal, 206(3):289297.

Ludtke, C. B., Dalla Costa, O. A., Roça, R. d. O., Silveira, E. T. F., Athayde, N. B., Araújo, A. P., . . Azambuja, N. C. (2012). Bem-estar animal no manejo pré-abate e a influência na qualidade da carne suína e nos parâmetros fisilógicos do estresse. Ciência Rural, 42(3):532-537.

Ludtke, C. B., Silveira, E. T. F., Bertoloni, W., Andrade, J. C., Buzelli, M. L. T., Bressa, L. R. \& Soares, G. J. D. (2010). Bem-estar e qualidade de carne de suínos submetidos a diferentes técnicas de manejo pré-abate. Revista Brasileira de Saúde e Produção Animal, 11(1):231-241.

Maiorka, P. C. (2012). O ensino da medicina veterinária no Brasil. Revista Conselho Federal de Medicina Veterinária, 557-11.

Melo, E. S., Amorim, W. R., Pinheiro, R. E. E., Corrêa, P. G. N., Carvalho, S. M. R., Santos, A. R. S. S., . . Sousa, F. V. (2018). Doenças transmitidas por alimentos e principais agentes bacterianos envolvidos em surtos no Brasil. PUBVET, 12(10):1-9.

Mendonça, P. S. M. \& Caetano, G. A. O. (2017). Abate de bovinos: Considerações sobre o abate humanitário e jugulação cruenta. PUBVET, 11(12):1196-1209.

Nielsen, B. L., Dybkjær, L. \& Herskin, M. S. (2011). Road transport of farm animals: effects of journey duration on animal welfare. Animal, 5(3):415-427.

Oliveira, C. B., Bortoli, E. d. C. \& Barcellos, J. O. J. (2008). Diferenciação por qualidade da carne bovina: a ótica do bem-estar animal. Ciência Rural, 38(7):2092-2096.

Roça, R. O. (2001). Abate humanitário de bovinos. Revista de Educação Continuada em Medicina Veterinária e Zootecnia do CRMV-SP, 4(2):73-85.

Santos-Filho, A. M. P. \& Mayrink, R. R. (2017). Medicina Veterinária Forense. In J. A. Velho, G. C. Geiser \& A. Espíndula, A. (Eds.), Ciências Forenses, uma introdução às principais áreas da criminalística moderna. Campinas, São Paulo: Millennium. 
Schrama, J. W., Van der Her, W., Gorssen, J., Henken, A. M., Verstegen, M. W. A. \& Noordhuizen, J. P. T. M. (1996). Required thermal thresholds during transport of animals. Veterinary Quarterly, 18(3):90-95.

Schwartzkopf-Genswein, K. S., Faucitano, L., Dadgar, S., Shand, P., González, L. A. \& Crowe, T. G. (2012). Road transport of cattle, swine and poultry in North America and its impact on animal welfare, carcass and meat quality: A review. Meat Science, 92(3):227-243.

Sobral, N. C., Andrade, E. N. \& AntonucciI, A. M. (2015). Métodos de insensibilização em bovinos de corte. Revista Científica de Medicina Veterinária, 251-10.

Strappini, A. C., Metz, J. H. M., Gallo, C. B. \& Kemp, B. (2009). Origin and assessment of bruises in beef cattle at slaughter. Animal, 3(5):728-736.

Velho, J. A., Geiser, G. C. \& Espindula, A. (2017). Ciências Forenses: Uma introdução às principais áreas da criminalística moderna. Campinas, São Paulo: Millenium Editora.

Recebido: 11 de fevereiro, 2019.

Aprovado: 1 de março, 2019.

Publicado: 18 de março, 2019.

Licenciamento: Este artigo é publicado na modalidade Acesso Aberto sob a licença Creative Commons Atribuição 4.0 (CCBY 4.0), a qual permite uso irrestrito, distribuição, reprodução em qualquer meio, desde que o autor e a fonte sejam devidamente creditados. 